Rakenteiden Mekaniikka (Journal of Structural Mechanics)

Vol. 50, No 3, 2017, pp. 323 - 325

https://rakenteidenmekaniikka.journal.fi/index

https://doi.org/10.23998/rm. 65071

(c) The author(s) 2017.

Open access under CC BY-SA 4.0 license.

\title{
Topology optimisation of in-line engine turbocharger bracket
}

Evgeniya Kiseleva ${ }^{1}$, Juho Könnö, Niclas Liljenfeldt, Teemu Kuivaniemi and Tero Frondelius

Summary. This article describes the use of the TOSCA software in the design process of a turbocharger bracket of a medium speed gas or diesel engine. TOSCA is a topology optimisation software from Dassault Systemes. This paper shows some intermediate optimized results as wells as the final design.

Key words: Wärtsilä, turbocharger bracket, FEM, topology optimization, Tosca

Received 26 June 2017. Accepted 17 August 2017. Published online 21 August 2017

\section{Introduction}

Genset dynamics is one of the most challenging aspects in the medium speed engine design process. There are a wide variety of different engine excitations to be considered from gas pressure [1], gear train [8], rotating [3] and oscillating masses [7] as well as all kinds of peculiar grid behaviors [5]. The concept calculation [4] tries to find the best compromise structure where the main natural frequencies are tuned to avoid the main excitations frequencies. The topology optimisation [2] of a turbocharger bracket with the TOSCA software can be used to achieve this.

Lastly the simulation data and requirement management had to be done correctly in order to utilize the full benefits of the topology optimisation. In this case it is done in the Wärtsila Digital Design Platform [6].

\section{Formulation of the problem for Tosca software}

Topology optimisation is a mathematical method that optimizes the material layout within a given design space, for a given set of loads, boundary conditions and constraints with the goal of maximizing the performance of the system. The current case had the problem that was described earlier. All current turbocharger bracket designs gave results where the natural frequency of the turbocharger was matching the firing frequency of the main engine case (the case where the engine is not mounted to a hull or is not in assembly

\footnotetext{
${ }^{1}$ Corresponding author. evgeniya.kiseleva@wartsila.com
} 


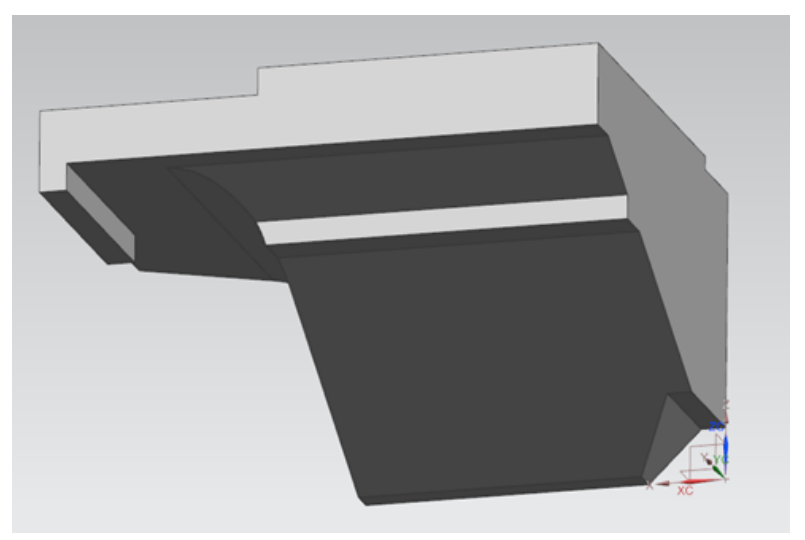

(a) Initial model for optimisation

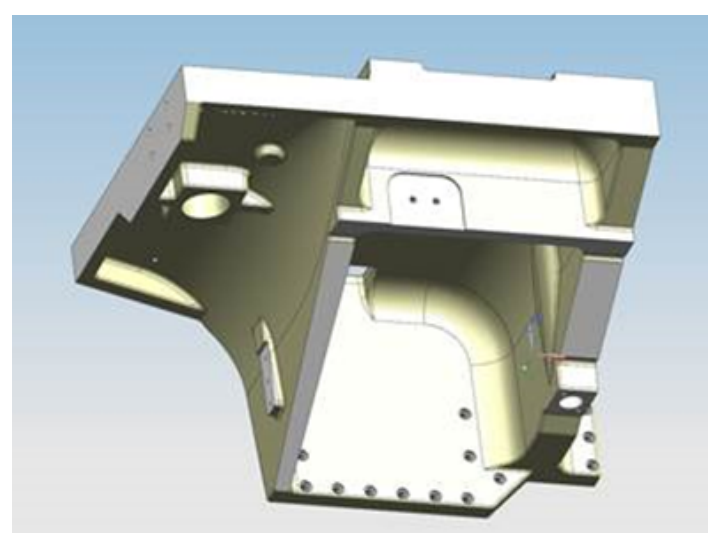

(b) Final design result

Figure 1. Initial model and final designed bracket after the optimisation.

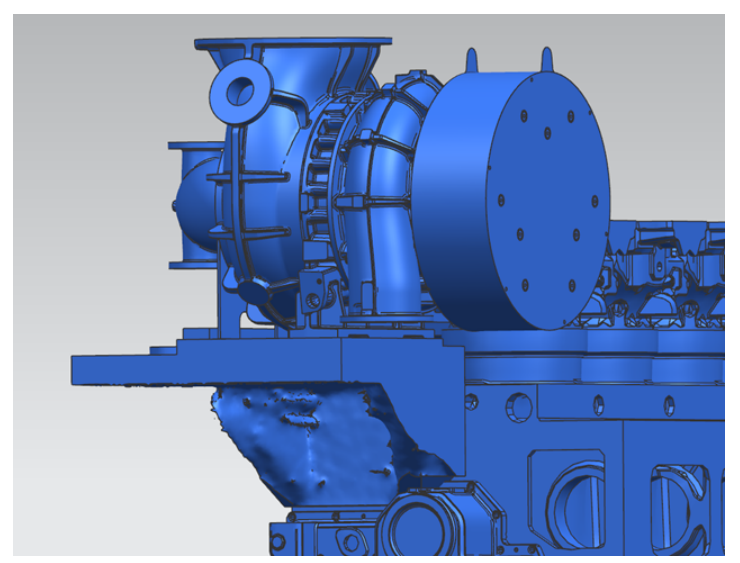

(a) Results given by Tosca

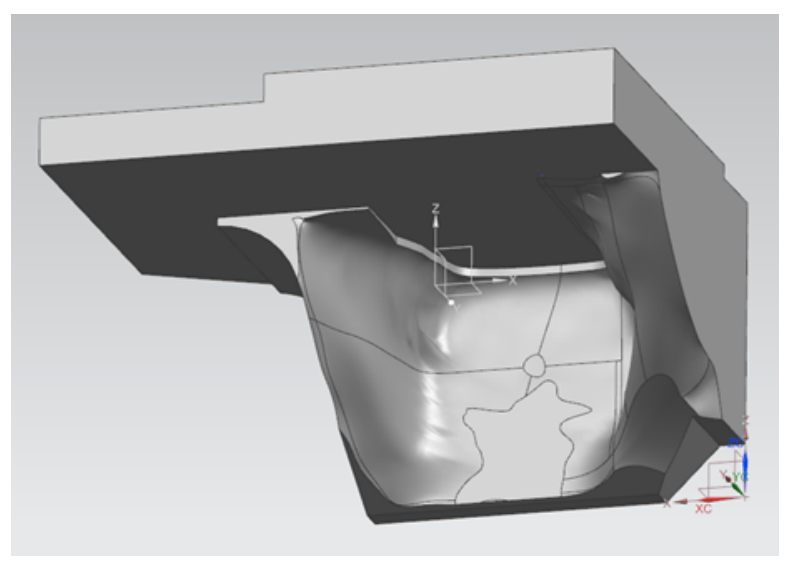

(b) Model prepared for further manual design work

Figure 2. Tosca optimization results.

with a genset). Therefore there were two options of design changes for the turbocharger bracket: to make the natural frequency higher than the firing frequency with a new turbocharger bracket design, or to make it lower. To check the first option, it was necessary to evaluate the maximum possible natural frequency of the turbocharger bracket within the maximum possible overall dimensions. The base model created for the initial natural frequency calculation is shown on Figure 1(a).

The results of the natural frequency calculation of turbocharger with the initial base bracket model showed that the sought-for natural frequency is 6-7 Hz higher than the firing frequency and that the other turbocharger natural frequency looks fine as well. Therefore the Tosca Software problem became very easy to define. The desired natural frequencies of turbocharger bracket should remain at its level, while the volume of the turbocharger bracket should be reduced as material is predefined for turbochrger: minimizing the volume with fixing natural frequencies of turbocharger bracket.

\section{Conclusions}

The results were obtained with Tosca and presented in Figure 2(a) and Figure 2(b). They required some further manual design work (such as bolt holes and auxilary systems holes) and a final checkup. The final model is shown on Figure 1(b). 
It can be concluded that topology optimisation brings a lot of added value to simulation driven design process through shortening the overall development time and making first time right designs. Like in this short paper, first the concept design is found by using the topology optimisation software Tosca. Secondly, follow-up work which is not presented here, is to make a final virtual validation calculation to the final model shown on Figure 1 (b) and make sure that the final design also fulfills the requirements.

\section{References}

[1] Jukka Aho and Tero Frondelius. Analyzing 3 TB field measurement data set. Rakenteiden Mekaniikka, 50(3):224-228, 2017. URL https://doi.org/10.23998/rm.64942.

[2] Alejandro R Díaaz and Noboru Kikuchi. Solutions to shape and topology eigenvalue optimization problems using a homogenization method. International Journal for Numerical Methods in Engineering, 35(7):1487-1502, 1992.

[3] Tero Frondelius, Pasi Halla-aho, and Antti Mäntylä. Crankshaft development with virtual engine modelling. In CIMAC Congress Helsinki, 2016.

[4] Johannes Heilala, Teemu Kuivaniemi, Juho Könnö, and Tero Frondelius. Concept calculation tool for dynamics of generator set common baseframe. Rakenteiden Mekaniikka, 50(3):353-356, 2017. URL https://doi.org/10.23998/rm.64925.

[5] Juho Könnö, Tero Frondelius, Thomas Resch, and Maria Jose Santos-Descalzo. Simulation based grid compliance. In CIMAC Congress Helsinki, 2016.

[6] Juho Könnö, Hannu Tienhaara, and Tero Frondelius. Wärtsilä digital design platform. Rakenteiden Mekaniikka, 50(3):234-238, 2017. URL https ://doi .org/10.23998/rm. 64621.

[7] Antti Korpela, Marko Jokinen, Teemu Kuivaniemi, and Tero Frondelius. W4L20 VEBIC genset dynamics — baseframe design. Rakenteiden Mekaniikka, 50(3):292-295, 2017. URL https://doi.org/10.23998/rm.64943.

[8] Teemu Kuivaniemi, Antti Mäntylä, Ilkka Väisänen, Antti Korpela, and Tero Frondelius. Dynamic gear wheel simulations using multi body dynamics. Rakenteiden Mekaniikka, 50(3):287-291, 2017. URL https://doi.org/10.23998/rm.64944.

Evgeniya Kiseleva, Juho Könnö, Niclas Liljenfeldt, Teemu Kuivaniemi and Tero Frondelius Wärtsilä

Järvikatu 2-4

65100 Vaasa

evgeniya.kiseleva@wartsila.com, juho.konno@wartsila.com,

niclas.liljenfeldt@wartsila.com, teemu.kuivaniemi@wartsila.com,

tero.frondelius@wartsila.com 